Cite this: Phys. Chem. Chem. Phys., 2013, 15, 14026

Received 9th May 2013,

Accepted 24th June 2013

DOI: $10.1039 /$ c3cp51963e

www.rsc.org/pccp

\section{Modeling the mechanism of glycosylation reactions between ethanol, 1,2-ethanediol and methoxymethanol $\dagger$}

\author{
Luis Miguel Azofra, ${ }^{\star a}$ Ibon Alkorta, ${ }^{a}$ Alejandro Toro-Labbéb and José Elguero ${ }^{a}$
}

The mechanism of the $\mathrm{S}_{\mathrm{N}} 2$ model glycosylation reaction between ethanol, 1,2-ethanediol and methoxymethanol has been studied theoretically at the B3LYP/6-311+G(d,p) computational level. Three different types of reactions have been explored: (i) the exchange of hydroxyl groups between these model systems; (ii) the basic catalysis reactions by combination of the substrates as glycosyl donors (neutral species) and acceptors (enolate species); and (iii) the effect on the reaction profile of an explicit $\mathrm{H}_{2} \mathrm{O}$ molecule in the reactions considered in (ii). The reaction force, the electronic chemical potential and the reaction electronic flux have been characterized for the reaction path in each case. Energy calculations show that methoxymethanol is the worst glycosyl donor model among the ones studied here, while 1,2-ethanediol is the best, having the lowest activation barrier of $74.7 \mathrm{~kJ} \mathrm{~mol}^{-1}$ for the reaction between this one and the ethanolate as the glycosyl acceptor model. In general, the presence of direct interactions between the atoms involved in the penta-coordinated TS increases the activation energies of the processes.

\section{Introduction}

The glycosylation reaction can be defined as the chemical condensation process in which one reactant with a suitable leaving group and an electrophilic carbon atom, the glycosyl donor, reacts with the other reactant with an unprotected nucleophilic group, the glycosyl acceptor, that attacks the electrophilic centre, to form the $\mathrm{C}-\mathrm{X}$ glycosidic bond. ${ }^{1-3}$ Despite the fundamental role of this reaction, the details of the glycosylation process remain relatively poorly understood. ${ }^{4,5}$ On the one hand, the $\mathrm{S}_{\mathrm{N}} 1$ mechanism was proposed by Rhind-Tutt and Vernon ${ }^{6}$ and subsequently refined by Lucas and Schuerch ${ }^{7}$ and by Lemieux and co-workers ${ }^{8}$ based on the general solvolysis reaction. ${ }^{9}$ At present, the suggested mechanism consists of the introduction of the oxocarbenium reaction intermediate along a reaction process involving this species by the following sequential steps: (i) irreversible ionization of the glycosyl donor; (ii) nucleophilic

\footnotetext{
${ }^{a}$ Instituto de Quimica Médica, I.Q.M.-C.S.I.C., Juan de la Cierva, 3, E-28006, Madrid, Spain.E-mail: luisazofra@iqm.csic.es; Web: http://are.iqm.csic.es; Fax: +34915644853

${ }^{b}$ Laboratorio de Química Teórica Computacional, QTC, Facultad de Química, Pontificia Universidad Católica de Chile, Casilla 306, E-9820436, Santiago de Chile, Chile

$\dagger$ Electronic supplementary information (ESI) available. See DOI: 10.1039/ c3cp51963e
}

attack by the glycosyl acceptor; and (iii) proton transfer. ${ }^{10}$ On the other hand, the $\mathrm{S}_{\mathrm{N}} 2$ mechanism is proposed when a $\mathrm{R}-\mathrm{O}^{-}$glycosyl acceptor attacks the electrophilic carbon atom of the glycosyl donor in a one-step chemical reaction characterized by the presence of a penta-coordinated transition state. ${ }^{11}$ Whitfield concluded in a recent paper that there is experimental evidence for the glycosylation reaction occurring through a bimolecular mechanism $\left(\mathrm{S}_{\mathrm{N}} 2\right){ }^{2}$ An important aspect that supports this thesis precisely is that the oxocarbenium species has not been found experimentally. However, the importance of the oxocarbenium species is that it could play the role of the intermediate or the transition state in a concerted reaction with more or less synchronicity. ${ }^{12-15}$

In the present article, simple model systems derived from cyclic carbohydrates (ethanol, 1,2-ethanediol and methoxymethanol) have been chosen with the objective to simulate the environment of the different carbon atoms in a monosaccharide compound in the ether formation which is similar to the glycosylation one. Initially, the hydroxylic interchange between the model systems outlined in Scheme 1 considering a $\mathrm{S}_{\mathrm{N}} 2$ reaction mechanism has been studied. In addition and following the same mechanism type, the formal glycosylation reaction has been examined by combination of the substrates as glycosyl donor models (neutral species) and acceptor ones (enolate species). Finally, the effect of an explicit $\mathrm{H}_{2} \mathrm{O}$ molecule on the latter has been studied. 


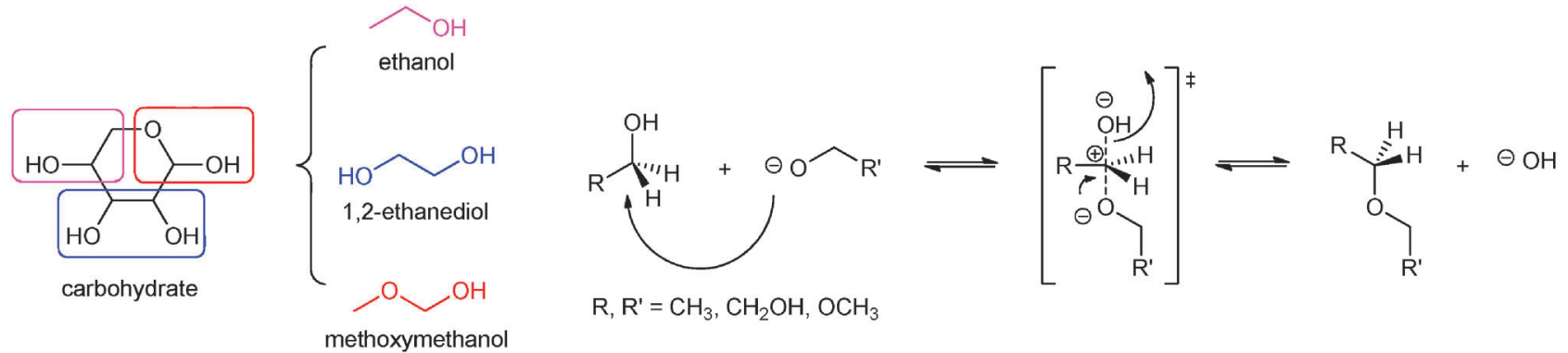

Scheme 1 On the left are simple model systems derived from cyclic carbohydrates: ethanol (purple); 1,2-ethanediol (blue); and methoxymethanol (red). On the right is the $\mathrm{S}_{\mathrm{N}} 2$ glycosylation mechanism scheme between the model systems (neutral/enolate species).

\section{Theoretical framework}

A chemical reaction can be understood in terms of geometrical changes of the molecular structures and reordering of the electron density involved in the process. Although geometrical and electronic activities are present along all the reactions, the use of the reaction force analysis ${ }^{16-23}$ allows us to partition the reaction coordinate of an elementary step into three regions (reactants, the transition state and products) where structural or electronic activity may prevail over the other. In this context, it has been shown in many different types of reactions that in the reactant and product regions the geometrical activity dominates, while in the TS region the electronic activity, bond strengthening-formation and/ or bond weakening-breaking processes prevail over the structural rearrangements. To characterize the electronic activity taking place during a chemical reaction, the electronic chemical potential ${ }^{24-26}$ and reaction electronic flux (REF) ${ }^{27-29}$ are going to be used within the framework of the reaction force analysis. The electronic chemical potential characterizes the reactivity of molecular systems by measuring the escaping tendency of electrons from an equilibrium distribution. ${ }^{24-26}$ Its negative first derivative with respect to the reaction coordinate, the reaction electronic flux, identifies the electronic activity during a chemical process. ${ }^{27-29}$

\section{Energy and reaction force}

A transition state (TS) is defined as a chemical entity along the intrinsic reaction coordinate $(\mathrm{IRC}=\xi)^{30,31}$ which is a stationary point and presents one imaginary frequency. It connects reactants and products through the path of minimum potential energy. Once the energy profile along the reaction path is defined, it is possible to evaluate the reaction force, $F(\xi)$, which is the negative first derivative of the total energy, $E$, with respect to the reaction coordinate (eqn (1)).

$$
F=-\frac{\mathrm{d} E}{\mathrm{~d} \xi}
$$

According to the Transition State Theory (TST), ${ }^{32}$ the energy profile of an elementary step presents three critical points: two minima, one for the reactants $\left(\xi_{\mathrm{R}}\right)$ and another for the products $\left(\xi_{\mathrm{P}}\right)$, and one maximum for the TS $\left(\xi_{\mathrm{TS}}\right)$. In addition, $F(\xi)$ exhibits two very important critical points: a minimum at $\xi_{1}$ and a maximum at $\xi_{2}$. Thus, we can define three regions: the first one, between $\xi_{\mathrm{R}}$ and $\xi_{1}$, where the reactants get prepared for the reaction mainly through structural reordering. The second one, limited by $\xi_{1}$ and $\xi_{2}$, where the TS is located exhibits a high electronic activity, and most formation and breaking of the bonds takes place here, so this region is mainly associated with electronic reordering. Finally, in the third region, between $\xi_{2}$ and $\xi_{\mathrm{P}}$, structural relaxation to obtain the products of the reaction prevails over electronic effects (see Fig. 1). ${ }^{16-23}$ Note that $\xi_{1}<\xi_{\mathrm{TS}}<\xi_{2}$.

Thus, the reaction force analysis provides an energy partition of the activation barrier in terms of the so called reaction works:

$$
\begin{aligned}
& E_{\mathrm{ac}}^{\rightarrow}=W_{1}+W_{2} \rightarrow W_{1}=-\int_{\xi_{\mathrm{R}}}^{\xi_{1}} F(\xi) \mathrm{d} \xi>0 \text { and } \\
& W_{2}=-\int_{\xi_{1}}^{\xi_{\mathrm{TS}}} F(\xi) \mathrm{d} \xi>0 \\
& E_{\mathrm{ac}}^{\leftarrow}=\left|W_{3}+W_{4}\right| \rightarrow W_{3}=-\int_{\xi_{\mathrm{TS}}}^{\xi_{2}} F(\xi) \mathrm{d} \xi<0 \text { and } \\
& W_{4}=-\int_{\xi_{2}}^{\xi_{\mathrm{P}}} F(\xi) \mathrm{d} \xi<0
\end{aligned}
$$

$W_{1}$ represents the amount of energy required to reorganize the system geometrically within the reactant region. Since $W_{2}$ is defined within the TS region, it might be mostly associated with

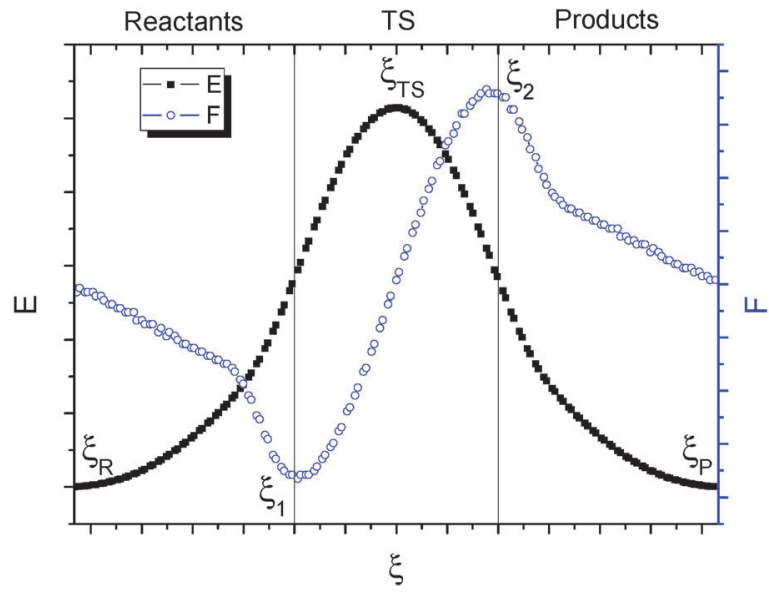

Fig. 1 The generic energy profile and its reaction force, $F(\xi)$, vs. the reaction coordinate, $\xi$, are represented with black squares and blue circles. The locations of the stationary points of the energy and $F(\xi)$ are indicated. Two vertical lines separate the reactants region (left), the TS region (centre) and the products region (right). 
the electronic activity necessary to reach the transition state. In this context the activation energy is interpreted in terms of contributions $W_{1}$, mostly associated with structural rearrangements, and $W_{2}$, typically mostly related to the electronic activity. $\left|W_{3}\right|$ and $\left|W_{4}\right|$ are used, by analogy with $W_{1}$ and $W_{2}$, to characterize the reverse barrier.

\section{Chemical properties based on conceptual DFT}

Conceptual DFT (CDFT) $)^{33-35}$ offers a range of theoretical tools that allow us to study and understand changes at the electronic level directly associated with physicochemical properties of the entities that are involved in the reaction. Thus, the electronic chemical potential, $\mu$, for a system of $N$ electrons is defined as the first derivative of the total energy with respect to $N$ when the external potential, $v(\vec{r})$, remains constant (eqn (4)). Note that the link between DFT and classical chemistry is obtained through the electronegativity, $\chi{ }^{24}$ as the negative of $\mu$. Considering that the number of electrons, $N$, is a discontinuous variable, the electronic chemical potential can be approximated through the application of finite differences and, by extension of the Hartree-Fock analysis, the Koopmans' theorem ${ }^{36}$ as the sum of the first ionization potential, $I$, and the electron affinity, $A$, multiplied by $-1 / 2$ or by the sum of the values of the highest occupied and lowest unoccupied molecular orbitals, $\varepsilon_{\mathrm{H}}$ and $\varepsilon_{\mathrm{L}}$ respectively, divided by 2 :

$$
\mu=-\chi=\left(\frac{\partial E}{\partial N}\right)_{v(\vec{r})} \approx-\left(\frac{I+A}{2}\right) \approx \frac{\varepsilon_{\mathrm{L}}+\varepsilon_{\mathrm{H}}}{2}
$$

Also, once the electronic chemical potential profile is defined, it is possible to evaluate the reaction electronic flux $(\mathrm{REF}), J(\xi)$, which is the negative first derivative with respect to the reaction coordinate (eqn (5)):

$$
J=-\frac{\mathrm{d} \mu}{\mathrm{d} \xi}
$$

The interpretation of the REF results from the analogy with classical thermodynamics. Positive values of $J(\xi)$ should be associated to spontaneous rearrangements of the electron density, this is driven by bond strengthening or forming processes; negative values of $J(\xi)$ indicate non-spontaneous rearrangements of the electron density that are mainly driven by bond weakening or breaking processes. ${ }^{37}$

Finally, all the properties described previously are of global nature, i.e., refer to molecular properties. However, the chemical reactivity resides in the atomic centers, and therefore it is necessary to define local indices. One of the most useful indices for the present study is the local index of electrophilicity (eqn (8)) that can be characterized thanks to the Fukui function. ${ }^{38}$ The electrophilicity index is obtained as the product of the global electrophilicity (eqn (6)), reported by Parr et al. ${ }^{39}$ by analogy with the power in classical electricity, and the nucleophilic Fukui function condensed to atom (eqn (7)): ${ }^{40}$

$$
\begin{gathered}
\omega \approx \frac{\mu^{2}}{2 \eta} \approx \frac{(I+A)^{2}}{8(I-A)} \approx \frac{\left(\varepsilon_{\mathrm{L}}+\varepsilon_{\mathrm{H}}\right)^{2}}{8\left(\varepsilon_{\mathrm{L}}-\varepsilon_{\mathrm{H}}\right)} \\
{f_{\mathrm{k}}^{+}}^{+} p_{\mathrm{k}}(N+1)-p_{\mathrm{k}}(N)
\end{gathered}
$$

$$
\omega_{\mathrm{k}}=f_{\mathrm{k}}^{+} \omega
$$

where the subscript $\mathrm{k}$ refers to a particular atom $\mathrm{k}, p_{\mathrm{k}}(N)$ is the electronic population on atom $\mathrm{k}$ in the neutral molecule whereas $p_{\mathrm{k}}(N+1)$ is the electronic population on atom $\mathrm{k}$ in the radical anion molecule. $\eta$ is the chemical hardness, ${ }^{41,42}$ which is the inverse of the softness, $S$, and can be defined as:

$$
\eta=S^{-1}=\left(\frac{\partial^{2} E}{\partial N^{2}}\right)_{v(\vec{r})} \approx-(I-A) \approx \varepsilon_{\mathrm{L}}-\varepsilon_{\mathrm{H}}
$$

\section{Computational methods}

All the geometries have been fully optimized with the hybrid Becke, ${ }^{43}$ three-parameter, Lee-Yang-Parr ${ }^{44}$ density functional (B3LYP) and Pople's basis set 6-311+G(d,p). ${ }^{45}$ The Synchronous Transit-Guided Quasi-Newton (STQN) Methods (QST2 and QST3 $)^{46}$ have been used to locate the TS. Frequency calculations have been carried out in order to verify that the obtained structures correspond to energetic minima or true TS. The intrinsic reaction coordinate (IRC) procedure, in which the reaction coordinate, $\xi$, is expressed in mass-weighted internal coordinates, ${ }^{47}$ was used in the description of the intermediate structures that connect the stationary points. All calculations were performed with the GAUSSIAN09 package. ${ }^{48}$ The Natural Bond Orbital (NBO) methodology ${ }^{49}$ has been employed to calculate the electronic population on the atomic centers with the NBO 3.1 program. $^{50}$

\section{Results and discussion}

This section has been divided into three parts: the first one will discuss the main results obtained for the hydroxylic interchange of ethanol, 1,2-ethanediol and methoxymethanol. In the second one, the problem will be extended to the model glycosylation reaction of the ethanol, 1,2-ethanediol and methoxymethanol with all the combinations of the conjugate basis of these three molecules, with the exception of the ethanol plus ethanolate reaction. In every one of these sections, the energy, reaction force, electronic chemical potential and REF, as well as their most significant results, will be discussed. Finally, in the third section and in line with the second one, the effect on the reaction profile of the presence of a $\mathrm{H}_{2} \mathrm{O}$ molecule will be discussed.

\section{Hydroxylic interchange in the substrates}

1.1. Energy and reaction force. The stationary points for the energy profiles (minima and TS) for the hydroxylic interchange mechanisms of (a) ethanol; (b) 1,2-ethanediol; and (c) methoxymethanol are gathered in Fig. 2. Several TS structures have been located for each reaction, which differ in the disposition of the $\mathrm{OH}^{-}$groups in the TS. The conformations of the $\mathrm{OH}^{-}$groups have been named 'in' or 'out' depending on whether hydrogen atoms point toward the bulky groups (left in Fig. 2) or not (right in Fig. 2). Two TS have been located for the $\mathrm{CH}_{3} \mathrm{CH}_{2} \mathrm{OH}+\mathrm{OH}^{-}$reaction ('in-out' and 'out-out'), two for 


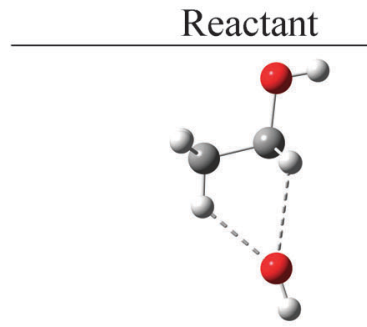

$\left(C_{1}\right)$

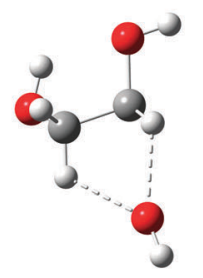

$\left(C_{1}\right)$

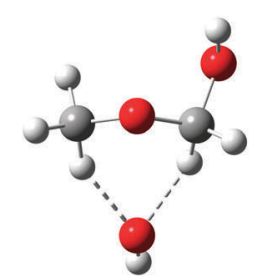

$\left(C_{1}\right)$
TS

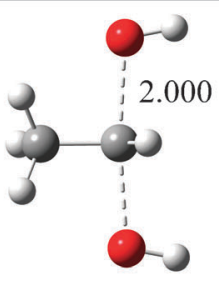

$\left(C_{s}\right)$ 'out-out'

(a) $\mathrm{CH}_{3} \mathrm{CH}_{2} \mathrm{OH}+\mathrm{OH}^{-}$

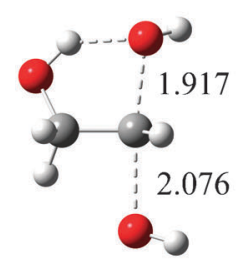

$\left(C_{1}\right)$ 'out-out'

(b) $\mathrm{CH}_{2} \mathrm{OHCH}_{2} \mathrm{OH}+\mathrm{OH}^{-}$

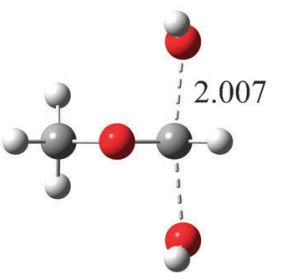

$\left(C_{s}\right)$ 'in-in'
Product

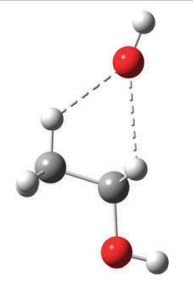

$\left(C_{1}\right)$

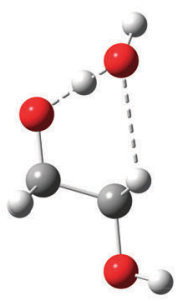

$\left(C_{1}\right)$

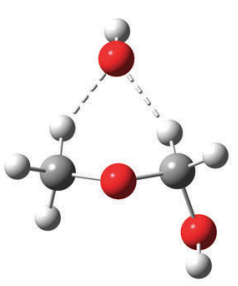

$\left(C_{1}\right)$

\section{(c) $\mathrm{CH}_{3} \mathrm{OCH}_{2} \mathrm{OH}+\mathrm{OH}^{-}$}

Fig. 2 Stationary points (minima and TS) for the selected hydroxylic interchange reactions for (a) ethanol; (b) 1,2-ethanediol; and (c) methoxymethanol, calculated at the B3LYP/6-311+G(d,p) computational level. For (b), an intermediate structure similar to those obtained in (a) and (c) at $\xi_{R}$ has been considered. The $C \ldots .0$ distances in the penta-coordinated TS are shown in $\AA$.

the $\mathrm{CH}_{2} \mathrm{OHCH}_{2} \mathrm{OH}+\mathrm{OH}^{-}$reaction ('in-out' and 'out-out'), and three for the $\mathrm{CH}_{3} \mathrm{OCH}_{2} \mathrm{OH}+\mathrm{OH}^{-}$reaction ('in-in', 'in-out' and 'out-out'). The most stable TS in each case ('out-out', 'out-out' and 'in-in', respectively) has been discussed in this section, while the geometries of all of them have been gathered in the ESI $†$ (Table S1). The energy, reaction force, electronic chemical potential and REF profiles have been represented in Fig. 3. In (a) and (c) cases, we found common profiles, while in the (b) case, the reactant zone exhibits the existence of residual processes that occur in some cases and present them as an asynchronous concerted mechanisms as previously described by Labet and co-workers. ${ }^{51}$ That is, whereas reactions (a) and (c) present the typical profiles of elementary reactions, for reaction (b) the profiles would be compatible with several and successive elementary steps. The reactant structure shown in Fig. 2(b), which corresponds to the reaction coordinate of $-8.74 \mathrm{amu}^{1 / 2}$ bohr, comes from a previous migration of the $\mathrm{OH}^{-}$anion to form a hydrogen bond with the hydroxyl groups of the 1,2-ethanediol (reaction coordinate between -9 and $-20 \mathrm{amu}^{1 / 2}$ bohr). Previously, a proton transfer occurs between one of the hydroxyl groups and the $\mathrm{OH}^{-}$anion (reaction coordinate between -20 and $-30 \mathrm{amu}^{1 / 2}$ bohr). Following this reaction from the reverse path, it is quite similar to a $\mathrm{S}_{\mathrm{N}} 2$ reaction described in a recent paper by Giri and co-workers, in which in the product zone, a migration appears in order to favor one hydrogen bond formation which stabilizes the system. ${ }^{52}$ Also, similar profiles are observed in the 1,2-ethanediol 'in-out' and methoxymethanol 'in-out' and 'out-out' mechanisms.

The lowest activation energy is observed in the hydroxyl exchange reaction of ethanol, (a), with $102.9 \mathrm{~kJ} \mathrm{~mol}^{-1}$ in both directions. In (b), the computed value of the activation is $76.0 \mathrm{~kJ} \mathrm{~mol}^{-1}$ for the direct process from the value of $\xi_{\mathrm{R}}=$ $-8.74 \mathrm{amu}^{1 / 2}$ bohr and determined with the curvature approximation (change from convexity to concavity) between the residual and the main steps. However, if we additionally include the 

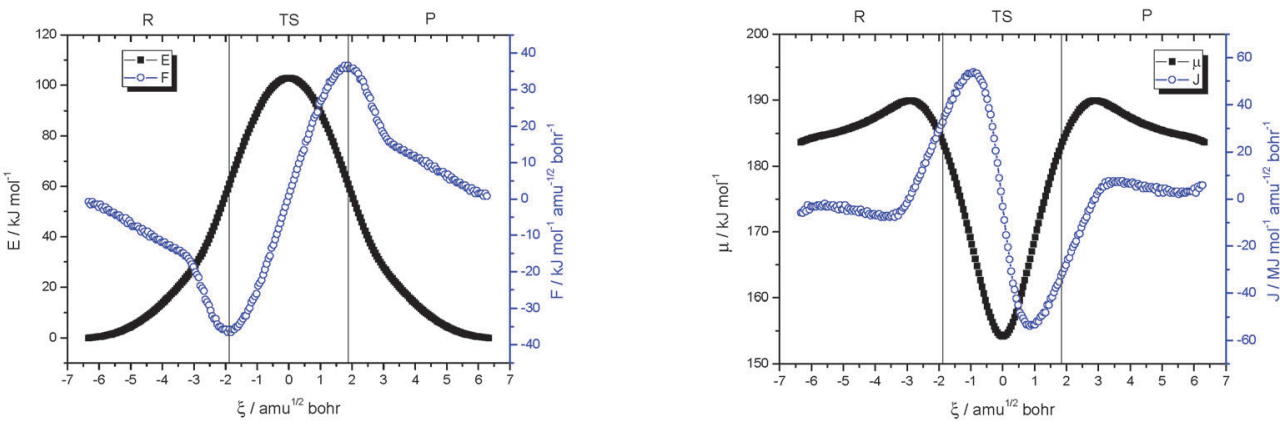

(a) $\mathrm{CH}_{3} \mathrm{CH}_{2} \mathrm{OH}+\mathrm{OH}^{-}$
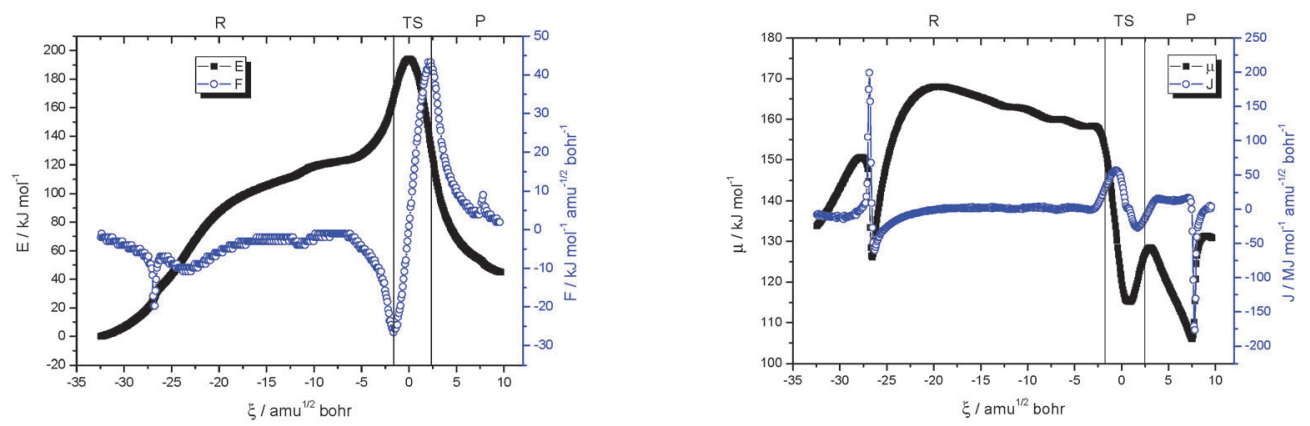

(b) $\mathrm{CH}_{2} \mathrm{OHCH}_{2} \mathrm{OH}+\mathrm{OH}^{-}$
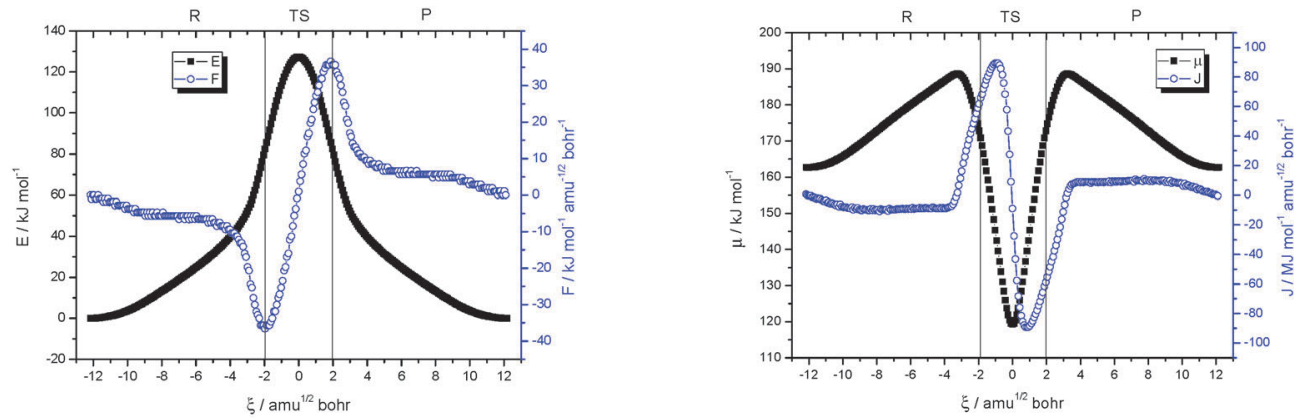

(c) $\mathrm{CH}_{3} \mathrm{OCH}_{2} \mathrm{OH}+\mathrm{OH}^{-}$

Fig. 3 Energy (black squares) in $\mathrm{kJ} \mathrm{mol}^{-1}$ and reaction force (blue circles) in $\mathrm{kJ} \mathrm{mol}^{-1} \mathrm{amu}^{-1 / 2} \mathrm{bohr}^{-1}$ profiles vs. the reaction coordinate in amu ${ }^{1 / 2}$ bohr (left). Electronic chemical potential (black squares) in $\mathrm{kJ} \mathrm{mol}^{-1}$ and REF (blue circles) in $\mathrm{MJ} \mathrm{mol}^{-1} \mathrm{amu}^{-1 / 2} \mathrm{bohr}^{-1}$ profiles vs. the reaction coordinate in amu ${ }^{1 / 2}$ bohr (right) in the hydroxylic interchange reactions, calculated at the B3LYP/6-311+G(d,p) computational level.

previous migration of the $\mathrm{OH}^{-}$(rotation and proton transfer), the activation energy goes up to $194.1 \mathrm{~kJ} \mathrm{~mol}^{-1}$ which corresponds to $\left(b^{\prime}\right)$ in Table 1. It is important to highlight that in the product structure of (b), see Fig. 2, the hydroxyl group produces the extraction of the acidic proton and the activation energy for the inverse process (the reverse reaction is not symmetric) is $149.1 \mathrm{~kJ} \mathrm{~mol}^{-1}$. In (c), the barrier is $127.3 \mathrm{~kJ} \mathrm{~mol}^{-1}$ for both directions. The partition of the activation energy in structural and electronic terms shows that for reactions (b) and (c) these terms are around $2 / 3$ and $1 / 3$, respectively, while in (a) they are about $1 / 2$ for each one. These percentages give us an idea about the fundamental differences of the mechanistic nature, explicitly, the presence of electronegative oxygen atoms (in the form of hydroxyl or ester functional groups) in (b) and (c), and their absence in (a). Furthermore, the quantitative similarity of $W_{2}$ between (a) and (c) mechanisms is consistent with the electronic activity deployed in these reactions. In fact, the total energy associated with the electronic activity $\left(W_{2}+\left|W_{3}\right|\right)$ is very similar in (a) and (c) being practically $90 \mathrm{~kJ} \mathrm{~mol}^{-1}$ in each case, and $76.7 \mathrm{~kJ} \mathrm{~mol}^{-1}$ for (b).

At $\xi_{1}$, the reaction force for (a) and (c) is $-36.6 \mathrm{~kJ} \mathrm{~mol}^{-1}$ $\mathrm{amu}^{-1 / 2} \mathrm{bohr}^{-1}$ for both, and at $\xi_{2}$ it is the same but with positive sign in each case. Fixing our attention on mechanism (b), the reaction force analysis provides important information in terms of the roles the hydrogen bonds play in this system. $F\left(\xi_{1}\right)$ in (b) is $-26.6 \mathrm{~kJ} \mathrm{~mol}^{-1} \mathrm{amu}^{-1 / 2} \mathrm{bohr}^{-1}$ and $F\left(\xi_{2}\right)$ is 
Table 1 Critical points of the intrinsic reaction coordinates of the energy $\left(\xi_{\mathrm{R}} \text { and } \xi_{\mathrm{P}}\right)^{a}$ and of the reaction force $\left(\xi_{1}\right.$ and $\left.\xi_{2}\right)$ in amu ${ }^{1 / 2}$ bohr. Activation and reaction energies and geometrical and electronic partitions in $\mathrm{kJ} \mathrm{mol}^{-1}$. In parentheses, the percentages with respect to the activation energy

\begin{tabular}{llllllllllll}
\hline Mech. & $\xi_{\mathrm{R}}$ & $\xi_{1}$ & $\xi_{2}$ & \multicolumn{1}{c}{$\xi_{\mathrm{P}}$} & \multicolumn{1}{c}{$E_{\mathrm{ac}}$} & $E_{\mathrm{ac}}^{\leftarrow}$ & \multicolumn{1}{c}{$E_{\mathrm{R}}$} & $W_{1}$ & $W_{2}$ & $\left|W_{3}\right|$ & $\left|W_{4}\right|$ \\
\hline (a) & -6.32 & -1.93 & 1.93 & 6.32 & 102.9 & 102.9 & 0.0 & $58.9(57)$ & $44.0(43)$ & $44.0(43)$ & $58.9(57)$ \\
(b) & -8.74 & -1.63 & 2.04 & 9.66 & 73.1 & 149.1 & -76.0 & $45.7(63)$ & $27.3(37)$ & $49.4(33)$ & $98.7(67)$ \\
$\left(\mathrm{b}^{\prime}\right)^{b}$ & -32.44 & - & - & - & 194.1 & - & -45.0 & - & - & - & - \\
(c) & -12.16 & -1.96 & 1.96 & 12.16 & 127.3 & 127.3 & 0.0 & $82.5(65)$ & $44.9(35)$ & $44.9(35)$ & $82.5(65)$
\end{tabular}

${ }^{a}$ By definition $\xi_{\mathrm{TS}}=0.00 \mathrm{amu}^{1 / 2}$ bohr. ${ }^{b}$ Actual reaction coordinate values if we consider the complete IRC.

$43.3 \mathrm{~kJ} \mathrm{~mol}^{-1} \mathrm{amu}^{-1 / 2} \mathrm{bohr}^{-1}$. The s-cis conformation in the reactant zone of the 1,2-ethanediol lacks adequate structural parameters for the existence of a hydrogen bond, as previously described in the literature for pseudo-five-membered rings 1-2 type interactions. ${ }^{53,54}$ However as the reaction evolves, a change in the $D_{\text {Occo }}$ dihedral angle is produced, transforming the system into a s-trans conformation. In addition, a strong hydrogen bond interaction between the $\mathrm{OH}^{-}$anion and one of the hydroxyl groups appears which increases the energy needed for the dissociation of the hydroxyl group. This is reflected by the large absolute value of $F\left(\xi_{2}\right)$ compared to $F\left(\xi_{1}\right)$. The breaking $\mathrm{C} \cdots \mathrm{O}$ distance in the TS for this reaction $(1.917 \AA)$ is the smallest calculated in this series. Thus, the presence of the strong hydrogen bond between the substrate and the $\mathrm{OH}^{-}$group increases the barrier of the hydroxyl exchange as well as the dissociation of this group.

1.2. Electronic chemical potential and REF. The analysis of the electronic chemical potential and the REF (Fig. 3) clearly shows the development of the reactive process. So, in (a) and (c), the systems start and finish in the zero-flux regimen as an indicator of no electronic activity, while in the TS zone, a maximum and a minimum is present for the REF directly associated with the formation of the fifth bond (C..OO) in the penta-coordinate TS, and the subsequent breakage of the opposite bond. For instance, around $\pm 60 \mathrm{MJ} \mathrm{mol}^{-1} \mathrm{amu}^{-1 / 2}$ bohr $^{-1}$ are the maximum and minimum values of the REF in (a), and in (c), an increment is registered up to $\pm 90 \mathrm{MJ} \mathrm{mol}^{-1}$ $\mathrm{amu}^{-1 / 2} \mathrm{bohr}^{-1}$. In the case of (b), it can be noted that in the reactant and product zones, different events occur to those that were observed in (a) and (c) reactions. Note that in (b), the proton transfers are clearly marked with two peaks rapidly escaping to the zero-flux regimen in both extremes of the profile. First of all, REF starts and finishes in the zero-flux regimen. In a short space of the intrinsic reaction coordinate, a peak in the REF through positive values is observed around $-28 \mathrm{amu}^{1 / 2}$ bohr (reactant zone) as a result of the first proton transfer. Concretely, the shared proton between the oxygen atom of the hydroxyl group and the $\mathrm{OH}^{-}$moieties evolves into a strengthening of the $\mathrm{O}-\mathrm{H}$ bond in the substrate. Later, in the product zone, a second proton transfer happens around $6 \mathrm{amu}^{1 / 2}$ bohr with a peak in the REF through negative values, associated in this case with a weakening of the $\mathrm{O}-\mathrm{H}$ bond in the substrate due to the sharing of the proton between the hydroxyl group and the $\mathrm{OH}^{-}$moieties. These two changes are also observed in the electronic chemical potential profile.
Both electronic properties present a common behavior with reactions (a) and (c) only in the TS zone.

\section{Model glycosylation reaction of the substrates: basic catalysis}

2.1. Energetics and electronic properties. Fig. 4 shows selected model glycosylation reactions, concretely, those with smallest and highest activation energies which belong to 1,2ethanediol as the glycosyl donor model and ethanolate and methoxymethanolate as glycosyl acceptors, respectively. In Fig. S1 of the ESI $\uparrow$ are gathered the three energy stationary points (minima and TS) for all the different glycosidic reactions indicated in Scheme 1. Likewise, in Fig. 5 are gathered the energy, reaction force, electronic chemical potential and REF profiles, and in Table 2 the quantitative reaction coordinates and energetic properties of every process. Note that all the structures have been considered without differentiation between main and residual processes, i.e., that the structure with the lowest value of $\xi$ refers to the reactant, $\xi=0.00 \mathrm{amu}^{1 / 2}$ bohr refers to the TS, and the one with largest value of $\xi$ refers to the product.

As can be compared, the energy and reaction force profiles of these mechanisms have simpler behaviors than what was obtained for the hydroxylic interchange, in the sense that, the substrates and the attacking/leaving anions do not exhibit large relative rotations and migrations which would produce more complicated curves.

Analyzing the reactions, one by one on the basis of the glycosyl donor model, it can be seen that for (a) and (b), where ethanol is the glycosyl donor substrate, the results are similar in the intrinsic reaction critical points with the exception of $\xi_{\mathrm{P}}$ in (b) due to the migration of the $\mathrm{OH}^{-}$forming two hydrogen bonds between the $\mathrm{CH}_{2}$ groups of the alcohol and the hemiacetal moieties. The activation energies are 128.5 and $134.1 \mathrm{~kJ} \mathrm{~mol}^{-1}$ and the reaction energies 54.1 and $36.7 \mathrm{~kJ} \mathrm{~mol}^{-1}$, respectively. In both cases, the values are larger than in the case of the hydroxylic interchange of the ethanol, which shows an activation barrier of $102.9 \mathrm{~kJ} \mathrm{~mol}^{-1}$. About the electronic chemical potential and the REF profiles, two observations can be mentioned: first, the main changes are located in the TS zone, therefore, reactants and products present zero-flux tendencies, and second, the electronic chemical potential is higher in the product than in the reactant areas. In the TS zone, the REF values reach a maximum and a minimum, which indicates the formation of the fifth bond in the penta-coordinated TS and glycoside compound. 

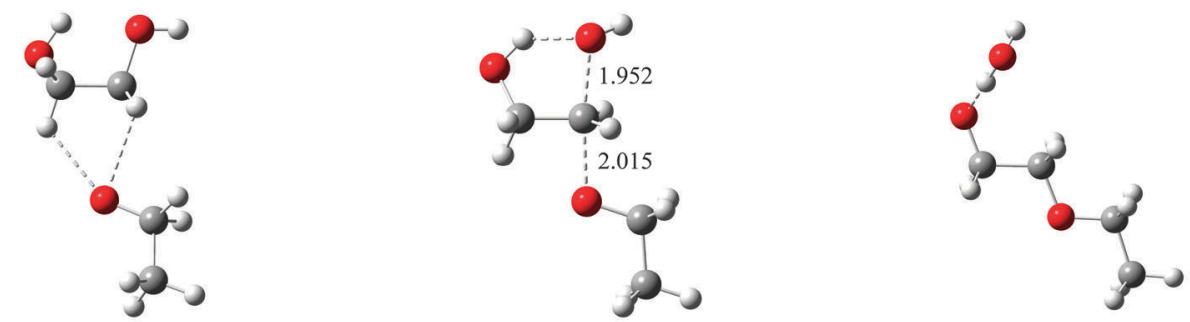

$$
\mathrm{CH}_{2} \mathrm{OHCH}_{2} \mathrm{OH}+\mathrm{CH}_{3} \mathrm{CH}_{2} \mathrm{O}^{-}\left(c, E_{a c}=74.7 \mathrm{~kJ} \mathrm{~mol}^{-1}\right)
$$
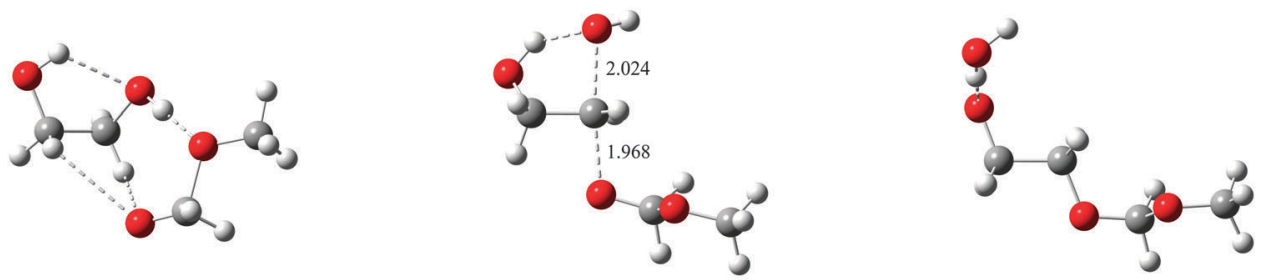

$$
\mathrm{CH}_{2} \mathrm{OHCH}_{2} \mathrm{OH}+\mathrm{CH}_{3} \mathrm{OCH}_{2} \mathrm{O}^{-}\left(e, E_{a c}=149.5 \mathrm{~kJ} \mathrm{~mol}^{-1}\right)
$$

Fig. 4 Stationary points (minima and TS) for selected model glycosylation reactions calculated at the B3LYP/6-311+G(d,p) computational level. The $C \ldots O$ distances in the penta-coordinated TS are shown in $\AA$.

Subsequently, one bond breaks to restore an $\mathrm{sp}^{3}$ carbon atom in the final ether derivative. $\Delta \mu\left(\xi_{\mathrm{P}}-\xi_{\mathrm{R}}\right)$ values are $24.5 \mathrm{~kJ} \mathrm{~mol}^{-1}$ for (a) and $18.1 \mathrm{~kJ} \mathrm{~mol}^{-1}$ for (b), i.e., the electronic escaping tendency is higher in products than in reactants. This fact can be explained as a consequence of the $\mathrm{OH}^{-}$anion not forming any strong hydrogen bond.

When the glycosyl donor model is 1,2-ethanediol, cases (c), (d) and (e), interesting results can be extracted. Small values of activation energies can be seen, $74.7 \mathrm{~kJ} \mathrm{~mol}^{-1}$ for (c) where the ethanolate acts as the glycosyl acceptor model, and $91.1 \mathrm{~kJ} \mathrm{~mol}^{-1}$ for (d) where the attacking anion is 2-hydroxyethanolate. In contrast, the activation energy in (e), where the glycosyl acceptor model is the anion of the hemiacetal, is $149.5 \mathrm{~kJ} \mathrm{~mol}^{-1}$ due to the existence of one additional hydrogen bond between the hemiacetal oxygen atom of the attacking molecule and the hydrogen atom of the leaving group which makes difficult the evolution of the reaction. This reaction shows a structural reorganization of the reactant similar to what has been previously described for the hydroxylic interchange of 1,2-ethanediol. Thus, interactions between the reactive anions with parts of the substrate that are not the reaction site produce an increment of the activation barriers.

The electronic chemical potential and the REF profiles indicate that the main electronic changes are located in the TS zone. The presence of a peak in the product region is associated with a proton transfer between the non-reactive hydroxyl group of 1,2-ethanediol and the leaving $\mathrm{OH}^{-}$. The $\Delta \mu\left(\xi_{\mathrm{P}}-\xi_{\mathrm{R}}\right)$ in these reactions presents negative values because, following our interpretation, the hydroxyl anion has formed a strong hydrogen bond with an acidic hydrogen atom that stabilizes it and decreases its electronic activity expressed as a reduced electronic escaping tendency. Cases (c) and (d) are the only ones for the glycosylation reactions that have got spontaneous values of reaction energies, -67.1 and $-33.8 \mathrm{~kJ} \mathrm{~mol}^{-1}$ for each mechanism.

Finally, cases (f)-(h), correspond to the reactions where the methoxymethanol acts as the glycosyl donor model and ethanolate, 2-hydroxyethanolate and methoxymethanolate as glycosyl acceptor models, respectively. In all these mechanisms, no migration or other secondary structural changes have been observed in the minima. With respect to the activation energies, they are in general the highest found in this study with values of $134.0,146.9$ and $148.8 \mathrm{~kJ} \mathrm{~mol}^{-1}$ for (f)-(h), respectively. Thus, the methoxymethanol is the worst glycosyl donor model among the ones studied here while 1,2-ethanediol is the best. The reaction energies are positive for the $(\mathrm{f})-(\mathrm{h})$ reactions. The electronic chemical potential and the REF profiles are similar with respect to the precedent results. An important peculiarity is that $\Delta \mu\left(\xi_{\mathrm{P}}-\xi_{\mathrm{R}}\right)$ is negative for (f) and (h), in contrast to what is observed in the rest of the reactions studied here, while it is positive for $(\mathrm{g})$.

The analysis of the $\mathrm{C} \cdots \mathrm{O}$ distances in the TS (Fig. 4 and Fig. S1, ESI $\dagger$ ) shows a direct relationship between the C..O distance in the leaving group and the activation energy, when the same glycosyl donor models are compared. Emphasizing on the C. .O distances outlined in Fig. 4 and Fig. S1 (ESI $\dagger$ ), a trend is observed when the activation energies of processes with the same glycosyl donor model are compared. Concretely, this is higher when the $\mathrm{C}$. . O distance of the leaving group is larger. About the O-C hemiacetal-electrophilic covalent bond in cases (f)-(h), i.e., when the methoxymethanol acts as the glycosyl donor model, a diminution of the distance in the TS with respect to the minima is registered. This fact indicates the potential role the oxocarbenium species could play as an 


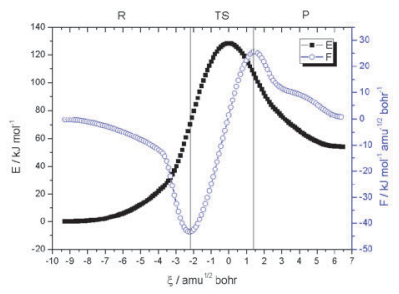

(a) $\mathrm{CH}_{3} \mathrm{CH}_{2} \mathrm{OH}+\mathrm{CH}_{2} \mathrm{OHCH}_{2} \mathrm{O}^{-}$

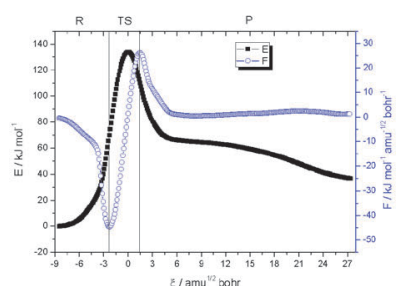

(b) $\mathrm{CH}_{3} \mathrm{CH}_{2} \mathrm{OH}+\mathrm{CH}_{3} \mathrm{OCH}_{2} \mathrm{O}^{-}$
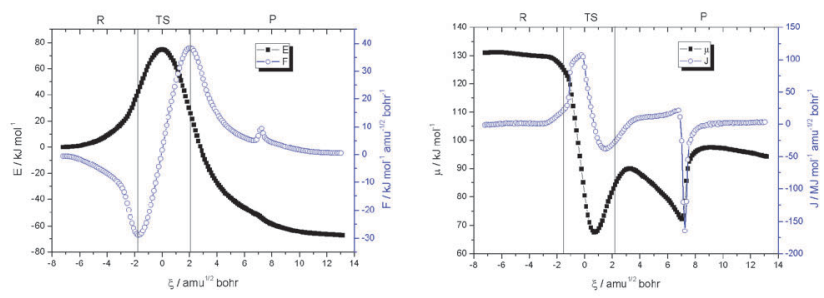

(c) $\mathrm{CH}_{2} \mathrm{OHCH}_{2} \mathrm{OH}+\mathrm{CH}_{3} \mathrm{CH}_{2} \mathrm{O}^{-}$
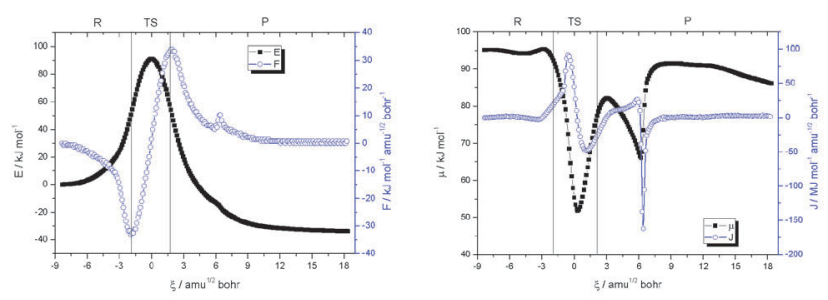

(d) $\mathrm{CH}_{2} \mathrm{OHCH}_{2} \mathrm{OH}+\mathrm{CH}_{2} \mathrm{OHCH}_{2} \mathrm{O}^{-}$
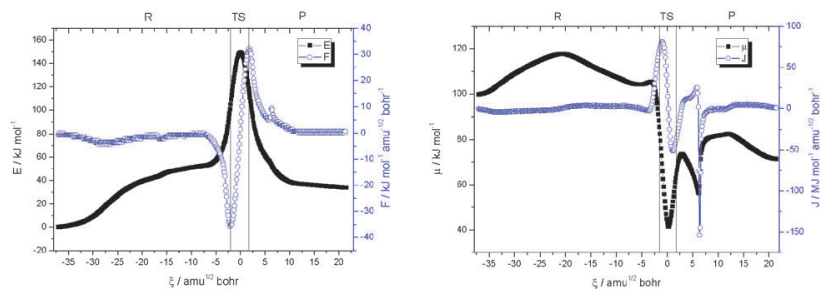

(e) $\mathrm{CH}_{2} \mathrm{OHCH}_{2} \mathrm{OH}+\mathrm{CH}_{3} \mathrm{OCH}_{2} \mathrm{O}^{-}$
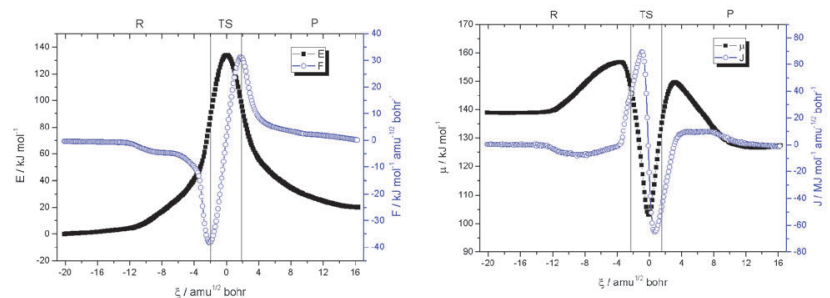

(f) $\mathrm{CH}_{3} \mathrm{OCH}_{2} \mathrm{OH}+\mathrm{CH}_{3} \mathrm{CH}_{2} \mathrm{O}^{-}$
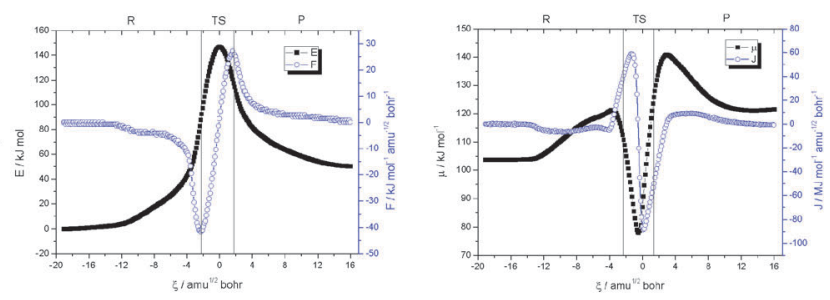

(g) $\mathrm{CH}_{3} \mathrm{OCH}_{2} \mathrm{OH}+\mathrm{CH}_{2} \mathrm{OHCH}_{2} \mathrm{O}$
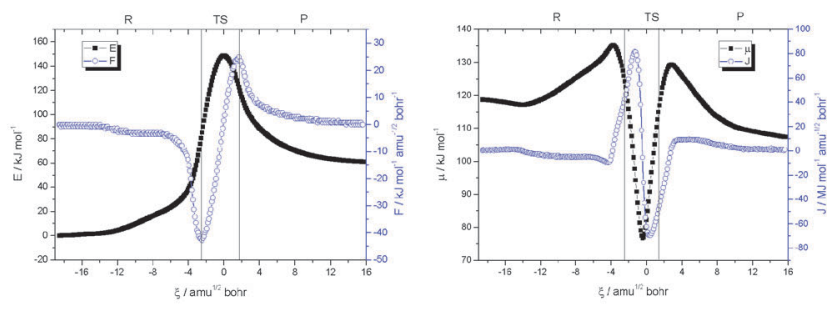

(h) $\mathrm{CH}_{3} \mathrm{OCH}_{2} \mathrm{OH}+\mathrm{CH}_{3} \mathrm{OCH}_{2} \mathrm{O}^{-}$

Fig. 5 Energy (black squares) in $\mathrm{kJ} \mathrm{mol}^{-1}$ and reaction force (blue circles) in $\mathrm{kJ} \mathrm{mol}^{-1} \mathrm{amu}^{-1 / 2} \mathrm{bohr}^{-1}$ profiles vs. the reaction coordinate in amu ${ }^{-1 / 2}$ bohr (left). Electronic chemical potential (black squares) in $\mathrm{JJ} \mathrm{mol}^{-1}$ and REF (blue circles) in $\mathrm{MJ} \mathrm{mol}^{-1} \mathrm{amu}^{-1 / 2}$ bohr $^{-1}$ profiles vs. the reaction coordinate in amu ${ }^{1 / 2}$ bohr (right) of all the glycosylation reaction models, calculated at the B3LYP/6-311+G(d,p) computational level.

Table 2 Intrinsic reaction critical points of the energy $\left(\xi_{\mathrm{R}} \text { and } \xi_{\mathrm{P}}\right)^{a}$ and of the reaction force $\left(\xi_{1}\right.$ and $\left.\xi_{2}\right)$ in amu ${ }^{1 / 2}$ bohr. Activation and reaction energies and geometrical and electronic partitions in $\mathrm{kJ} \mathrm{mol}^{-1}$. In parentheses, the percentages with respect the activation energy

\begin{tabular}{|c|c|c|c|c|c|c|c|c|c|c|}
\hline Mech. & $\xi_{\mathrm{R}}$ & $\xi_{1}$ & $\xi_{2}$ & $\xi_{\mathrm{P}}$ & $E_{\mathrm{ac}}$ & $E_{\mathrm{R}}$ & $W_{1}^{b}$ & $W_{2}^{b}$ & $\left|W_{3}\right|^{b}$ & $\left|W_{4}\right|^{b}$ \\
\hline (a) & -9.30 & -2.20 & 1.43 & 6.49 & 128.5 & 54.1 & $70.1(55)$ & $58.4(45)$ & $22.3(30)$ & $52.2(70)$ \\
\hline (b) & -8.49 & -1.69 & 1.47 & 27.34 & 134.1 & 36.7 & $97.3(73)$ & $36.8(27)$ & $23.9(25)$ & $73.5(75)$ \\
\hline (c) & -7.21 & -1.73 & 2.07 & 13.15 & 74.7 & -67.1 & 42.7 (57) & $32.0(43)$ & $48.7(34)$ & $93.0(66)$ \\
\hline (d) & -8.34 & -1.93 & 1.93 & 18.36 & 91.1 & -33.8 & $50.6(56)$ & $40.5(44)$ & $40.7(33)$ & $84.2(67)$ \\
\hline (e) & -37.05 & -2.13 & 1.80 & 21.49 & 149.5 & 33.8 & $100.8(67)$ & 48.7 (33) & 34.9 (30) & $80.8(70)$ \\
\hline (f) & -20.12 & -2.15 & 1.79 & 16.31 & 134.0 & 20.2 & $82.1(61)$ & $52.0(39)$ & $34.8(31)$ & $79.0(69)$ \\
\hline (g) & -19.10 & -2.30 & 1.61 & 16.07 & 146.9 & 50.3 & 87.7 (60) & $59.2(40)$ & $26.4(27)$ & $70.1(73)$ \\
\hline (h) & -18.55 & -2.47 & 1.69 & 15.76 & 148.8 & 61.2 & $85.2(57)$ & $63.5(43)$ & $26.2(30)$ & $61.4(70)$ \\
\hline
\end{tabular}

${ }^{a}$ By definition $\xi_{\mathrm{TS}}=0.00 \mathrm{amu}^{1 / 2}$ bohr. ${ }^{b}$ Values without differentiation between main and residual processes.

intermediate or a transition state in this particular case of the $\mathrm{S}_{\mathrm{N}} 2$ glycosylation reaction model. ${ }^{12-15}$ The $\mathrm{O}-\mathrm{C}$ hemiacetal-electrophilic covalent distance in (f)-(h) reactions has an average value of 1.405, 1.345 and $1.403 \AA$ for reactants, the TS and products, respectively. 
In any case, the complete separation never occurs (the $\mathrm{S}_{\mathrm{N}} 1$ mechanism), as is indicated in our energy profiles that are characteristic of bimolecular processes. The geometries of all these TSs have been gathered in the ESI $\dagger$ (Table S2).

The geometric $\left(W_{1}\right.$ and $\left.\left|W_{4}\right|\right)$ and electronic $\left(W_{2}\right.$ and $\left.\left|W_{3}\right|\right)$ contributions to the activation energies gathered in Table 2 can be grouped better on the basis of the glycosyl acceptor model than on the glycosyl donor one. Thus, in the mechanisms that use as attacking molecule the ethanolate (c and f) and 2-hydroxyethanolate (a, d and g) $W_{1}-W_{2}$ are around $60: 40 \%$ and $\left|W_{3}\right|-\left|W_{4}\right|$ around $30: 70 \%$; and in the case of methoxymethanolate (b, e and h) around $70: 30 \%$ and $30: 70 \%$, with the exception of $W_{1}-W_{2}$ for (h), which is exactly $57: 43 \%$. In all the situations, the electronic contribution to the reaction barrier is always less than the geometrical one. The electronic contribution for the mechanism occurring with the same glycosyl donor model is always depleted when secondary processes are present.

2.2. Local index of electrophilicity in the carbon atom of the glycosyl donor model. The electrophilicity index profiles (see ESI, $\uparrow$ Fig. S2) indicate that the processes start with the highest values of this property (between 4 and $10 \mathrm{~kJ} \mathrm{~mol}^{-1}$ ), with the exception of the case (e) due to the structural situation commented above. Along the reaction path, it decreases to zero maintaining this tendency not only in the TS zone, but also in the product area. This fundamental observation gives us an idea about the kinetic nature of the mechanisms, that is, although the inverse process could have low values of activation barrier, and the process could thermodynamically occur, it is kinetically unfavorable.

\section{The presence of a $\mathbf{H}_{2} \mathrm{O}$ molecule in the model glycosylation reactions between the substrates}

The insertion of a $\mathrm{H}_{2} \mathrm{O}$ molecule in the reaction mechanism as a potential receptor of the leaving hydroxyl group provides interesting information about the role that other molecular moieties similar to water could play. The effect produced by the bare $\mathrm{H}_{2} \mathrm{O}$ molecule is dual: in some cases we found an increase of the activation energies while in other cases, there is a large or small decrease. For instance, in reaction (a), the activation barrier decreases by $34.0 \mathrm{~kJ} \mathrm{~mol}^{-1}$ since the leaving hydroxyl anion in the TS and the product is stabilized by the formation of the $\mathrm{OH}\left(\mathrm{H}_{2} \mathrm{O}\right)^{-}$aggregate. Additionally, the reaction energy decreases too. In contrast, in reaction (b) there is an important increment of the activation energy, because the attacking group in the reactants migrates to interact with the hydroxyl group of the substrate, showing an increment of $15.6 \mathrm{~kJ} \mathrm{~mol}^{-1}$. Severe consequences occur for (c)-(e), when the 1,2-ethanediol acts as glycosyl donor model, in which the events are altered with respect to the corresponding mechanisms without the single $\mathrm{H}_{2} \mathrm{O}$ molecule. Thus, in mechanisms (c) and (d) without $\mathrm{H}_{2} \mathrm{O}$ there is no migration of the reactant substrate, but it occurs in its presence, while the opposite happens in (e). For this reason the variation of the $E_{\mathrm{ac}}$ between the processes without and with a $\mathrm{H}_{2} \mathrm{O}$ molecule is $-113.1,-86.7$ and $73.7 \mathrm{~kJ} \mathrm{~mol}^{-1}$ for (c)-(e), respectively (Table 3 ). The reaction energies follow the same pattern with variations of $-97.2,-75.1$ and $80.3 \mathrm{~kJ} \mathrm{~mol}^{-1}$.
Table 3 Activation and reaction energies and geometrical and electronic partitions in $\mathrm{kJ} \mathrm{mol}^{-1}$ for the glycosylation reaction models without and with a bare $\mathrm{H}_{2} \mathrm{O}$ molecule

\begin{tabular}{|c|c|c|c|c|c|c|}
\hline \multirow[b]{2}{*}{ Mech. } & \multicolumn{2}{|c|}{ Without $\mathrm{H}_{2} \mathrm{O}$} & \multicolumn{4}{|c|}{ With $\mathrm{H}_{2} \mathrm{O}$} \\
\hline & $E_{\mathrm{ac}}$ & $E_{\mathrm{R}}$ & $E_{\mathrm{ac}}$ & $E_{\mathrm{R}}$ & $\Delta E_{\mathrm{ac}}$ & $\Delta E_{\mathrm{R}}$ \\
\hline (a) & 128.5 & 54.1 & 94.5 & -12.8 & 34.0 & 66.9 \\
\hline (b) & 134.1 & 36.7 & 149.7 & 28.8 & -15.7 & 7.9 \\
\hline (c) & 74.7 & -67.1 & 187.7 & 30.2 & -113.1 & -97.2 \\
\hline (d) & 91.1 & -33.8 & 177.8 & 41.3 & -86.7 & -75.1 \\
\hline (e) & 149.5 & 33.8 & 75.8 & -46.5 & 73.7 & 80.3 \\
\hline (f) & 134.0 & 20.2 & 141.1 & 7.4 & -7.1 & 12.8 \\
\hline (g) & 146.9 & 50.3 & 145.7 & 33.7 & 1.2 & 16.6 \\
\hline (h) & 148.8 & 61.2 & 145.1 & 42.5 & 3.6 & 18.7 \\
\hline
\end{tabular}

Finally, in the mechanisms where the glycosyl donor model is the hemiacetal compound, similar activation energies have been observed. In this case, the $\mathrm{H}_{2} \mathrm{O}$ molecule is associated in the reactive process initially with the attacking anionic oxygen atom in the reactants evolving towards the interaction with the leaving hydroxyl group in the products. The geometries of all these TS have been gathered in the ESI $\dagger$ (Table S3). Also, energy, reaction force, electronic chemical potential and REF profiles $v s$. the reaction coordinate associated with this section are gathered in the ESI $\dagger$ (Fig. S3).

\section{Conclusions}

The reaction mechanism of models of $\mathrm{S}_{\mathrm{N}} 2$ glycosylation formation from simple systems derived from cyclic carbohydrates (ethanol, 1,2-ethanediol and methoxymethanol) has been studied. The hydroxylic interchange for the 1,2-ethanediol shows a high activation barrier of $194.1 \mathrm{~kJ} \mathrm{~mol}^{-1}$ due to the secondary processes involved in the reactant zone $\left(\mathrm{OH}^{-}\right.$and proton transfer), while in the hydroxylic interchange of ethanol, the activation is only $102.9 \mathrm{~kJ} \mathrm{~mol}^{-1}$, the lowest for this reaction type studied here. The reaction force analysis offered crucial information to rationalize the activation processes. In all cases studied here, the structural rearrangements are more important than the electronic ones $\left(W_{1}>W_{2}\right)$.

Energy calculations show that the methoxymethanol is the worst glycosyl donor model among the ones studied here, while 1,2-ethanediol is the best, having the lowest activation barrier of $74.7 \mathrm{~kJ} \mathrm{~mol}^{-1}$ for the reaction between this one and the ethanolate as the glycosyl acceptor model. The effect produced by the bare $\mathrm{H}_{2} \mathrm{O}$ molecule is dual: in some cases we found an increase of the activation energies while in other cases, there is a large or small decrease. In general, the presence of direct interactions between the atoms involved in the penta-coordinated TS increases the activation energies of the processes.

Finally, the changes in REF are located mainly in the TS region, with the exception of the presence of some peaks directly associated with pseudo proton transfers (proton shared between two electronegative atoms). Also, the presence of the $\mathrm{OH}^{-}$anion makes the $\mathrm{sp}^{3}$ carbon atom very electrophilic. In the case of the reactions studied here, the electrophilicity index is high in reactants, and along the reaction path, it decreases to 
zero maintaining this tendency not only in the TS region, but also in the product region, showing that the inverse process is kinetically unfavorable.

\section{Acknowledgements}

LMA thanks the MICINN for a PhD grant (No. BES-2010031225). LMA, IA and JE also thank MINECO (Project No. CTQ2012-35513-C02-02) and the Comunidad Autónoma de Madrid (Project MADRISOLAR2, ref. S2009/PPQ-1533) for continuing support. ATL wishes to thank Fondecyt through project No. 1130072 for financial support. Gratitude is also due to the CTI (C.S.I.C.) and CESGA for allocation of computer time.

\section{References}

1 G.-J. Boons and K. J. Hale, Organic Synthesis with Carbohydrates, Blackwell Publishing, London, 2000.

2 D. M. Whitfield, Carbohydr. Res., 2012, 356, 180.

3 S. Bufali and P. H. Seeberger, Org. Reac., Wiley, 2004.

4 L. Bohé and D. Crich, C. R. Chim., 2011, 14, 3.

5 L. K. Mydock and A. V. Demchenko, Org. Biomol. Chem., 2010, 8, 497.

6 A. J. Rhind-Tutt and C. A. Vernon, J. Chem. Soc., 1960, 4637. 7 T. J. Lucas and C. Schuerch, Carbohydr. Res., 1975, 39, 39.

8 R. U. Lemieux, K. B. Hendriks, R. V. Stick and K. James, J. Am. Chem. Soc., 1975, 97, 4056.

9 S. Winstein, E. Grunwald and L. L. Ingraham, J. Am. Chem. Soc., 1948, 70, 821.

10 T. Nukada, A. Bérces and D. M. Whitfield, Carbohydr. Res., 2002, 337, 765.

11 M. Sato, H. Yamataka, Y. Komeiji, Y. Mochizuki, T. Ishikawa and T. Nakano, J. Am. Chem. Soc., 2008, 130, 2396.

12 J. Gildersleeve, R. A. Pascal and D. Kahne, J. Am. Chem. Soc., 1998, 120, 5961.

13 D. Crich, Acc. Chem. Res., 2010, 43, 1144.

14 M. T. C. Walvoort, J. Dinkelaar, L. J. van den Bos, G. Lodder, H. S. Overkleeft, J. D. C. Codée and G. A. van der Marel, Carbohydr. Res., 2010, 345, 1252.

15 M. G. Beaver, S. B. Billings and K. A. Woerpel, Eur. J. Org. Chem., 2008, 771.

16 A. Toro-Labbé, J. Phys. Chem. A, 1999, 103, 4398.

17 P. Jaque and A. Toro-Labbé, J. Phys. Chem. A, 2000, 104, 995.

18 J. Martínez and A. Toro-Labbé, Chem. Phys. Lett., 2004, 392, 132.

19 A. Toro-Labbé, S. Gutiérrez-Oliva, M. C. Concha, J. S. Murray and P. Politzer, J. Chem. Phys., 2004, 121, 4570.

20 S. Gutiérrez-Oliva, B. Herrera, A. Toro-Labbé and H. Chermette, J. Phys. Chem. A, 2005, 109, 1748.

21 P. Politzer, A. Toro-Labbé, S. Gutiérrez-Oliva, B. Herrera, P. Jaque, M. Concha and J. Murray, J. Chem. Sci., 2005, 117, 467.

22 E. Rincón and A. Toro-Labbé, Chem. Phys. Lett., 2007, 438, 93.

23 L. M. Azofra, I. Alkorta, J. Elguero and A. Toro-Labbé, J. Phys. Chem. A, 2012, 116, 8250.
24 R. G. Parr, R. A. Donnelly, M. Levy and W. E. Palke, J. Chem. Phys., 1978, 68, 3801.

25 R. G. Parr and W. Yang, Annu. Rev. Phys. Chem., 1995, 46, 701.

26 J. Padmanabhan, R. Parthasarathi, V. Subramanian and P. K. Chattaraj, J. Phys. Chem. A, 2007, 111, 1358.

27 B. Herrera and A. Toro-Labbé, J. Phys. Chem. A, 2007, 111, 5921.

28 E. Echegaray and A. Toro-Labbé, J. Phys. Chem. A, 2008, 112, 11801.

29 S. Vogt-Geisse and A. Toro-Labbé, J. Chem. Phys., 2009, 130, 244308.

30 K. Fukui, J. Phys. Chem., 1970, 74, 4161.

31 K. Fukui, Acc. Chem. Res., 1981, 14, 363.

32 K. J. Laidler and M. C. King, J. Phys. Chem., 1983, 87, 2657.

33 R. G. Parr and W. Yang, Density-Functional Theory of Atoms and Molecules, Oxford University Press, Oxford, 1994.

34 P. Geerlings, F. De Proft and W. Langenaeker, Chem. Rev., 2003, 103, 1793.

35 H. Chermette, J. Comput. Chem., 1999, 20, 129.

36 T. Koopmans, Physica, 1934, 1, 104.

37 M. L. Cerón, E. Echegaray, S. Gutiérrez-Oliva, B. Herrera and A. Toro-Labbé, Sci. China: Chem., 2011, 54, 1982.

38 P. Hohenberg and W. Kohn, Phys. Rev., 1964, 136, B864.

39 R. G. Parr, L. v. Szentpály and S. Liu, J. Am. Chem. Soc., 1999, 121, 1922.

40 A. Toro-Labbé, Theoretical Aspects of Chemical Reactivity, Elsevier, Amsterdam, 2007, vol. 19.

41 R. G. Parr and R. G. Pearson, J. Am. Chem. Soc., 1983, 105, 7512.

42 R. Pearson, J. Chem. Sci., 2005, 117, 369.

43 A. D. Becke, J. Chem. Phys., 1993, 98, 5648.

44 C. T. Lee, W. T. Yang and R. G. Parr, Phys. Rev. B: Condens. Matter Mater. Phys., 1988, 37, 785.

45 M. J. Frisch, J. A. Pople and J. S. Binkley, J. Chem. Phys., 1984, 80, 3265.

46 C. Peng, P. Y. Ayala, H. B. Schlegel and M. J. Frisch, J. Comput. Chem., 1996, 17, 49.

47 C. Gonzalez and H. B. Schlegel, J. Phys. Chem., 1990, 94, 5523. 48 M. J. Frisch, G. W. Trucks, H. B. Schlegel, G. E. Scuseria, M. A. Robb, J. R. Cheeseman, G. Scalmani, V. Barone, B. Mennucci, G. A. Petersson, H. Nakatsuji, M. Caricato, X. Li, H. P. Hratchian, A. F. Izmaylov, J. Bloino, G. Zheng, J. L. Sonnenberg, M. Hada, M. Ehara, K. Toyota, R. Fukuda, J. Hasegawa, M. Ishida, T. Nakajima, Y. Honda, O. Kitao, H. Nakai, T. Vreven, J. A. Montgomery, J. E. Peralta, F. Ogliaro, M. Bearpark, J. J. Heyd, E. Brothers, K. N. Kudin, V. N. Staroverov, R. Kobayashi, J. Normand, K. Raghavachari, A. Rendell, J. C. Burant, S. S. Iyengar, J. Tomasi, M. Cossi, N. Rega, N. J. Millam, M. Klene, J. E. Knox, J. B. Cross, V. Bakken, C. Adamo, J. Jaramillo, R. Gomperts, R. E. Stratmann, O. Yazyev, A. J. Austin, R. Cammi, C. Pomelli, J. W. Ochterski, R. L. Martin, K. Morokuma, V. G. Zakrzewski, G. A. Voth, P. Salvador, J. J. Dannenberg, S. Dapprich, A. D. Daniels, Ö. Farkas, J. B. Foresman, J. V. Ortiz, J. Cioslowski and D. J. Fox, Gaussian, Inc., Wallingford, CT, 2009. 
49 F. Weinhold and C. R. Landis, Valency and Bonding. A Natural Bond Orbital Donor-Acceptor Perspective, Cambridge Press, Cambridge, 2005.

50 E. D. Glendening, A. E. Reed, J. E. Carpenter, F. Weinhold.

51 V. Labet, C. Morell, A. Toro-Labbe and A. Grand, Phys. Chem. Chem. Phys., 2010, 12, 4142.
52 S. Giri, E. Echegaray, P. W. Ayers, A. S. Nuñez, F. Lund and A. Toro-Labbé, J. Phys. Chem. A, 2012, 116, 10015.

53 I. Rozas, I. Alkorta and J. Elguero, J. Phys. Chem. A, 2001, 105, 10462.

54 L. M. Azofra, I. Alkorta, J. Elguero and P. L. A. Popelier, Carbohydr. Res., 2012, 358, 96. 